\title{
Russian literature lesson in the modern information and educational space
}

\author{
Viktor F. Chertov ${ }^{1, *}$ and Alla M. Antipova ${ }^{1}$ \\ ${ }^{1}$ MSPU, Department of Literature Teaching Methods, Moscow, Russia
}

\begin{abstract}
This article covers the current issue concerning cultivation of a pupil's reading and information culture during the literature learning process. The authors highlight the particularities of literature lessons where pupils are being introduced to fine literature and develop their communicative and informational competencies: focusing on the spheres of life not normally touched upon in other lessons, analyzing literary text as a complex sign system, and using types of texts other than literary ones. The authors also reveal insights into the concept of literature textbooks developed with the direct involvement of the authors, including the view of literature as a metaphor of the world and a special learning style; focus on dialogism, reflexivity, and interaction; and orientation toward the achievement of individual learning results. The content and methodology of the textbooks are analyzed through management of the high quality information-cognitive activities of pupils.
\end{abstract}

The most important task of modern school education is to prepare its pupils to function in the formation society. The SCONUL operational team (Society of College, National and Universities Libraries) singled out the main types of information skills that every person in the information society must obtain: how to fill information gaps; build information search strategies; search and find access to information; compare and evaluate information received from various sources; manage, implement and transfer information by various means; and carry out synthesis and collection of relevant information using it as a base for new knowledge. Russian scholars add to this list such skills as communication in the information society and computer literacy. Pupils master this set of skills throughout the entire period of school learning.

Literature lessons play a special role in the formation of information and reading culture. The development of information and communicative technologies that allow us to become part of the boundless information space have considerable influence on the management of the literature learning process: goals, selection of learning material and its structuring principles, subject textbooks, preparation of literature lessons, and selection of educational methods and technologies.

The development of literature as a school subject will depend on how convincing the suggested methodological solutions on the issue of introducing pupils to the particular information contained in literary texts will appear. The term "literary information" was transferred to aesthetics from information theory. It reveals the specificity of a literary message, which lies in the fact that it makes an emotional impact and is transferred by means of individualized literary images. This specificity is comprehended through such terms of information theory as originality, redundancy, order, text, code, sign, and so on. [2]. Unlike literary information, scientific information is characterized as logically structured information received on the basis of empirical, rational knowledge of objective reality.

The second difference between literary and scientific information lies in the optional character of the latter [3]. Modern scientists note that during "colossal growth of sign culture", when "logic intellect, i.e. the intellect that uses logic operations" [4] is formed, art recedes. It is turning into some kind of museum relic, cultural heritage, which is acknowledged by the global community, and yet communicating with it is not a daily living need and it can be easily replaced by communication with other sources of information.

Literary information is placed into the category of mass social information. This is its difference from scientific information that "in order to perceive aesthetic information, one must have aesthetic sense common to all people, on different scales. However, the perception of scientific information, along with other types of social information, requires a certain level of professional training; thus, aesthetic information represents mass information, while its scientific counterpart is a kind of special information" [5]. It might seem that this is the main advantage of literary information over scientific; it does

Corresponding author: victorchertov@mail.ru 
not require any additional training and it can be perceived by anybody, even those not prepared to perceive it. However, this advantage relates to a major issue, which is especially topical in the modern information space, where a consumer of literary information needs the following, at the very least:

- a clear understanding of the purpose of such information, what this information gives in exchange of or in addition to other information (motivation),

- well mastered navigational skills in a boundless information sea, proper experience of perceiving literary information and, as much as possible, a developed artistic taste (competencies).

Literature lessons in secondary school contribute greatly to the fulfillment of these tasks (more or less efficiently). Moreover, when we speak about literature lessons, we see the lesson not only as a basic form of learning process management. What is meant here is also the possible results of education, such as the life lesson a learner can gain from works of literature. These results may not be obvious, and, moreover, one cannot evaluate these results on the basis of a current and final assessment of graduates.

Golubkov V. V., following the ideas of Buslaev F. I., Galakhov A. D. and Stoyunin V. Y., asked such questions as "...what is the value of knowledge in human nature and society that learners get from works of literature? What can literature give from the point of view of a learner's emotional education? What kind of skills and abilities does it help develop? What is the main factor that determines the work of a teacher here?" [6]

"Why Am I Going to a Literature Lesson Today" is the name of a publication by famous teacher, Ayzerman L. S. [7]. This is the question that a teacher with many years of working experience asks himself.

"Why am I going to a literature lesson today? What can this piece of fiction give me? What new information will I know about the world and myself?" - these are the questions that a modern pupil can ask themselves and their teacher.

What aspects should we consider today while preparing for a literature lesson where pupils are being introduced to literary information?

First of all, during literature lessons, pupils become acquainted with the classic and modern works of Russian and world literature that give us insight into the spheres of life not normally touched upon in other lessons. This is the search of man for moral knowledge, a world of their own feelings, the emotional part of a person, and a world of artistic creation. Moreover, these are the everlasting, philosophic questions that concern each person regardless of their age, personality type, or sphere of professional activity. Learners can receive this literary information by means of direct emotional perception of a piece of fiction (reading by the teacher, a professional elocutionist, or a learner specifically trained for this beforehand). This kind of perception can be enough to create a special atmosphere in the lesson, or to prove the thesis on the individuality of a poet's art world, or to summarize the results of work on the dramatic reading of a piece of fiction. The experience of perceiving a piece of fiction in a literature lesson is not only the thing that determines the efficiency of the following work on literary text, but it is also the beginning of individual communication with works of literature. In an art image, as in a work of fiction, there is always something left unspoken, incomplete, which only partly contradicts the conditions of a regular lesson, where everything is to be rationally managed, planned and fulfilled. Sometimes it is necessary to intentionally make a stop (or at least make a pause) in order to save the emotional impression from being spoiled by an overly detailed analysis.

Secondly, literary text as a complex sign system with its specific code system, which often prefers alogism to common sense and logic, allows us to solve difficult, thoroughly pragmatic tasks of developing a learner's logical thinking. Analysis and interpretation of a literary text in literature lessons, in particular, suggest the following:

- resolution of difficult problems concerning the decoding of literary information, including the development of the ability to see the author's logic in the plot's structure, composition, selection and alteration of descriptions, episodes, images, specific tools and literary details, which quite often aim to distract and confuse the reader;

- correlation of one's own view on the characters, events, senses, emotions depicted in a piece of fiction with the author's view (or character's view) and the view of other interpretations of the work;

- presentation of individual judgments, evaluations, characteristics in the form of connected verbal or written utterance.

In this regard, explicit verbal or written utterance on a piece of fiction (its image, description, episode, fragment, etc.), built with consideration for formal logic, unintentionally considers the genre, compositional and stylistic peculiarities of the piece of writing, at least on the level of using the text's fragments and full or partial quoting. A literature lesson gives pupils the opportunity to be creative together with the author (not only in literary art). Most likely, this experience will only appear meaningful for a few people. Nonetheless, this opportunity to make the first attempt at writing (under a teacher's guidance) may become the first step on the road to a creative career, which is proven by the examples of many Russian poets, writers, critics, literary scholars, journalists, historians, directors, and art critics.

Thirdly, all information received by pupils in literature lessons is, obviously, connected with literary texts, which represents the base and fundamental core of the school course. However, working with a text goes hand in hand with the aspects of literary studies. In grades 5-8, this mostly means occasional reference to literature epochs, 
styles, and biographical facts about writers. In grades 9-11, literary works are discussed in terms of historical and cultural context, a writer's work context, and more attention is given to literary process, traditions, innovations, literary polemic, styles, and literary magazines. Moreover, besides literary text itself, such things as literary critics, publicist writing, research studies and reference materials also come into the view of learners. The above mentioned modern aspects of literature study in a lesson were reflected in the program and subject textbooks under the editorship of Chertov V. F., and have been used in Russian schools since 2008 (the line of training packages is part of the series "Academic School Textbook", which was developed in compliance with the Federal State Educational Standard. The training package includes: the program for grades 5-9, methodological materials for each grade's "Literature Lesson", phonochrestomathy (with methodical recommendations), and workbooks. Textbooks for grades 5-9 are recommended to be used in the educational process by the Ministry for Education and Science of the Russian Federation (M.: Prosveshcenie. Currently, the development of textbooks for grades 10-11 is being completed.).

It should be mentioned that the educational paradigm shift, accessibility of the information and educational environment defined the reconsideration of the view on subject textbooks and the expansion of its functions. The textbook is seen as a "learning activity program developed through time and space, built as a consistent approach to the fulfillment of school subject tasks by means of didactic cognitive activity and learning process management" [8]. Being the foundational set of learning and teaching on the subject, the textbook along with the learning program defines the logic of the learning process and reflects the particularity of the methodological concept developed by the textbook's authors. The team of authors (Chertov V. F., Ippolitova N. A., Trubina L. A., Antipova A. M., Mamonova I. V., Manykina A. A.) suggested a new approach to the study of literary texts and the selection of approaches for working with them, conditioned by viewing literature as a metaphor of the world, a particular way of perceiving life and imagining a literary picture of the world, which differs considerably from its scientific counterpart by its high scale of emotional impact, metaphoricity, polysemy, associativity and incompleteness $[9 ; 10]$. This concept is consistently implemented in the textbooks designed on its basis.

The authors believe that the primary objective is the development of an interest in reading and stimulation of the individual reader's motivation. The fulfillment of this objective precedes all other objectives of literary education. Thus, the primary importance in a literature lesson is given to the management of the literary perception process. In all literature lessons and self-study activities, the main focus is the development of the ability to read, comment, analyze and interpret literary texts, mastering the various algorithms of understanding the meanings included in a literary text, and the subsequent creation of one's own texts, presentation of one's own evaluations, and judgments on texts that have been read. A special role is given to dramatic reading, which is necessary to evoke interest in the book and its writer and deepen the individual perception of the piece of literature.

The key theoretical literary issues, defined specifically for each grade, set the main direction of work with literary texts, dictate the selection of aspects of its analysis and types of activities on the study of literary texts, theory, and history of literature knowledge: $5^{\text {th }}$ grade - literary image in literature; $6^{\text {th }}$ grade - image of man in literature; $7^{\text {th }}$ grade - the plot as a metaphor for life; $8^{\text {th }}$ grade - the literary world of a work of literature; $9^{\text {th }}-$ the writer's literary world, literary styles (here begins the studying of literature on a historical, literary basis); $10^{\text {th }}$ grade literary process, literature in a historical, cultural context; $11^{\text {th }}$ grade - literary process, traditions and innovations. Here, theoretical literary concepts are seen not only as a tool to comprehend literary texts; many terms, used in literature lessons, can also be applied in various spheres of knowledge and communication.

The communication of learners with works of literature in literature lessons is necessary not only as a fact of acquaintance with true literary values, but also as a necessary communication experience, a dialogue with writers (Russian and international writers, modern authors and representatives of other epochs), and, additionally, a dialogue with teachers and classmates.

The implementation of a system-based activity approach to the organization of literary education supposes the involvement of pupils in various types of learning activities, molded by a system of questions and tasks. For example: tasks oriented on searching for additional information (the "Search for information" section); tasks connected with the preparation of verbal utterances, messages, speeches and reports (the "Public speaking" section); tasks aimed at the development of the reader's ability to form impressions and value judgments on a read text (the "Point of view" section); tasks connected with the interpretation of a literary text, scientific and literary, including dramatic reading, role-play reading, illustration creation, screen play, etc. (the "Creative reading" section); and others.

It should be noted that the suggested questions and tasks, including those marked as individual tasks, take into account the interests of pupils in certain kinds of activities and suppose the usage of modern information searching and processing technologies (virtual excursions, presentations, working with search engines). The basic content of studying materials is reflected in the textbook (along with recommended activities), while pupils from the information-learning environment select additional content. Thus, the invariant content of literary education is deepened and enriched.

Reference section materials, included in all textbooks, develop the skill of working with a subject's information 
environment. The methodological apparatus of the textbooks includes knowledge aimed at the development of the ability to work with various sources of information, search for it, analyze it, and use it for self-activity. The reference section includes, aside from a "Concise Dictionary of Literary Terms", comments on literary texts, a brief overview of famous literary scholars, artists, composers, actors, and translators, who are referred to throughout the textbook. In order to form and develop the learner's competencies, it is important to provide them with links to biographic, bibliographic, explanatory and other dictionaries, as well as web sources, where they can find necessary information on writers, literary style, magazines, museums, monuments, reviews on theatrical performances, and so on. Let us introduce examples of tasks: prepare a virtual excursion or a presentation (Mayakovsky's work on "Okna ROSTA", "Shukshin as an actor", "Directorial works of Shukshin V. M." and others), arrange a virtual excursion to Veshinskaya Cossack Village, and more.

A new direction of working with e-sources is the appeal for forums and blogs, which are popular among pupils. Learners are invited to participate in literary contests and games conducted on certain websites, and in discussion and writing of so-called "fanfics" (fan fiction works).

The textbook program includes such unique (specifically marked) sections as "The World of the Word", "Commentaries", and "Case studies", which expand the learner's vocabulary, develop the literary function of word analysis, develop the skills of working with dictionaries, etc. The theme of many case studies is aimed at the improvement of the learner's information culture, and enrichment of the reader's interests and skills of working with educational, scientific and literary texts: "Review on a Work of Literature" ( $5^{\text {th }}$ grade), "Dramatic Reading as a Means of Interpretation", "Report on the Life and Work of a Writer" ( $6^{\text {th }}$ grade $)$, "Review on a Read Work of Literature" ( $7^{\text {th }}$ grade), "An Essay on Literary Theme" ( $8^{\text {th }}$ grade $)$, "Essay Work" ( $9^{\text {th }}$ grade $)$, "Research and Creative Projects on Literature" $\left(10^{\text {th }}\right.$ grade $)$, "Intertextual Links Within a Literary Work" ( $11^{\text {th }}$ grade), and others.

As the specific characteristics of teaching methods in the information-educational environment are the subjective position of a learner and are aimed towards the achievement of individual learning results, reflexivity, communication, interaction [11], it is important to give learners an opportunity to gain the experience of fulfilling project, research and search tasks. Let us demonstrate several examples: with your classmates, prepare the collection "Image of one of the ancient Russian cities reflected in Russian poetry"; with your classmates prepare a wall newspaper, composed of the best reviews on pieces of literature; hold a survey to find out what kinds of books about children your classmates read, and others ( $5^{\text {th }}$ grade); with your classmates, prepare a collection of literary songs, and others $\left(6^{\text {th }}\right.$ grade); prepare a recommendation list of detective stories for your classmates, recommendations on sci-fi books for adult readers (parents, teachers) and your classmates, and others ( $7^{\text {th }}$ grade); prepare a message on "Songs of the Great Patriotic War" (World War II) (with illustrative materials, song records, film fragments), and others ( $8^{\text {th }}$ grade); with your classmates, prepare an outline for phono-chrestomathy ("Ballads based on the poems of Pushkin A.S."), and others ( $9^{\text {th }}$ grade); prepare an outline for selected poems by Fet A.A. (with titles, a short introductory article for the collection) $\left(10^{\text {th }}\right.$ grade $)$, and others.

Thus, the methodological apparatus of textbooks trains the learner's ability to select and carry out analysis and synthesis of information on a certain theme; develops the ability to work with various types of texts on different data storage devices; improves computer and media literacy; develops the ability to find and apply knowledge; develops intentional reading skills; develops the ability to present one's point of view; gives an opportunity to arrange group activity and communication between members of the teaching and learning processes; gives an opportunity to individualize the educational process; considers the actualization of the learner's life experience; corresponds to the learner's specific age characteristics; and sets intraand cross subject links. The described set of literature subject textbooks executes a methodological system aimed at mastering the key competencies: common culture and informational and communicative competencies in the sphere of identity formation, which is compliant with the modern requirements for the management of the literature learning process under the information-learning environment and correlates with the step-by-step formation of universal learning activities.

These textbooks model the scenario of learning activity in literature lessons, which can be interpreted as commonsensism, i.e. "modern common activity of equal minds of teacher and learners, aimed at the creation, but not reproduction of a sense basis of the studied subject, problem, tasks, aspect, etc." [12].

The appeal to various types of classroom activities in literature lessons creates an environment for the development of a person who is emotionally rich and intellectually developed, capable of easily navigating the informational space, and ready to fulfill the most difficult tasks, which assume taking a creative approach and using nonstandard solutions.

\section{References}

1. A.V. Osin, Multimedia in Education: Informational Support Context (2005)

2. Esthetics. Dictionary (Under the general editorship of A.A. Belyaev and others) (1989)

3. Y.M. Lotman, The Structure of Literary Text (1998)

4. A.A. Zinovjev, I Dream about a New Human (2007) 
5. A.V. Sokolov, Introduction to the Theory of Social communication (1996)

6. V.V. Golubkov, Teaching Literature in Prerevolutionary Secondary School (1946)

7. L.S. Ajzerman, Why Am I Going to a Literature Lesson Today. Notes of a Language and Literature Teacher Who Worked in a School for Half a Century (2005)

8. I.K. Zhuravlev, The Peculiarities of Textbooks on School Subjects with the Leading component "Methods of Activity" and Formation of EmotionallyValuable Relationships. What should a textbook look like: didactic design concepts: in 2 parts(Edited by I.Y. Lerner, N.M. Shakhmaev, Part 2) (1992)
9. Literature work program for grades 5-9 (Edited by V.F. Chertov) (2011)

10. V.F. Chertov, Literature in School, 4 (2007)

11. E.O. Ivanova, I.M. Osmolovskaya, Theory of Education in Information Society (2011)

12. S.P. Lavlinskiy, Technology of Literary Education. Commutative Activity Approach (2003) 